\title{
A STUDY ON PRESCRIBING PATTERN IN GERIATRIC PATIENTS
}

\author{
NATARAJ GR*, BHARATHI DR
}

Department of Pharmacology, SJM College of Pharmacy, Chitradurga, Karnataka, India. Email: itsnattu007@gmail.com

\author{
Received: 03 April 2019, Revised and Accepted: 11 July 2019
}

\begin{abstract}
Objective: The objective of this study was to study the prescribing pattern in geriatric patients.

Methods: A prospective study was carried out for a period of 4 years with one of the objectives to study the prescribing pattern in geriatric patients ( $\geq 65$ years). The information was collected, from patients admitted to various departments of tertiary care hospital and old-age home at Chitradurga. Sociodemographic, economic, and clinical diagnosis and medication details were collected from medical records in a pre-structured case record form. The medications were classified based on Anatomical Therapeutic Chemical classification system.

Results: A total number of 526 geriatric patients were enrolled during the study period. Young older patients (75.29\%) and male subjects (55.89\%) were predominant. Multiple morbidity conditions were more in the present study. Among the diseases diagnosed, circulatory system (I00-I99) affecting was more $41.83 \%$. Prescriptions found with a sum total of 3228 formulations with 357 active drugs. About $56.27 \%$ of patients received $\geq 6$ medications (polymedication) and an average of 6.14 drugs per prescription. Usage of parenterals (53.06\%) was more among dosage forms. Prescriptions with alimentary tract, metabolism (A) (26.96\%), and general anti-infective (J) (19.08\%) class of drugs were common. Among individual drugs, pantoprazole (A02BC02), paracetamol (N02BE01), and ceftriaxone (J01DD04) were found more frequent in prescriptions.
\end{abstract}

Conclusion: The study concludes the need of intellect prescribing practice, to install more rational therapy among geriatric patients.

Keywords: Prescribing pattern, Geriatrics, Anatomical Therapeutic Chemical classification, Prescription.

(C) 2019 The Authors. Published by Innovare Academic Sciences Pvt Ltd. This is an open access article under the CC BY license (http://creativecommons. org/licenses/by/4. 0/) DOI: http://dx.doi.org/10.22159/ajpcr.2019.v12i9.33378

\section{INTRODUCTION}

Drug utilization research was defined by the WHO, in 1977, as "the marketing, distribution, prescription, and use of drugs in a society, with special emphasis on the resulting medical, social, and economic consequences" [1-3]. The principle aim of drug utilization research is to facilitate the rational use of drugs in population.

The share of India's population ages 60 and older is projected to climb from $8 \%$ in 2010 to $19 \%$ in 2050 , according to the United Nations Population Division. By mid-century, India's 60 and older population is expected to encompass 323 million people, a number greater than the total U.S. population in 2012. This profound shift in the share of older Indians - taking place in the context of changing family relationships and severely limited old-age income support - brings with it a variety of social, economic, and health-care policy challenges [4].

Advances in health-care system have increased the life expectancy and hence increased the geriatric population. The high prevalence of geriatric morbidity has led to increased drug usage. Elderly population has a higher prevalence of chronic and multiple diseases, which has been addressed by the health professionals. Therefore, geriatric population is a major recipient of drug therapy and poses special problems [1]. Interindividual differences in age-related pharmacokinetic and pharmacodynamic changes as well as comorbid conditions have to be considered while prescribing medicines in elderly population [5]. The present research on prescribing pattern will provide an insight into existing drug usage and ensure rationality of drug therapy.

\section{METHODS}

A prospective study was carried out on geriatric $\geq 65$ years, inpatients of Basaveshwara Medical College Hospital and Research Centre (BMCH and RC) (750-bedded hospital) and old-age home at Chitradurga, for a period of 4 years (July 2014-June 2018).

\section{Study criteria}

Inclusion criteria

The following criteria were included in the study:

- Patients of either gender of $\geq 65$ years of age

- Inpatients at hospital and patients at old-age home

- $\quad$ Patients who were willing to give an informed consent.

Exclusion criteria

The following criteria were excluded from the study:

- Patients admitted to causality, or

- Patients admitted to intensive care unit, or

- Patients who failed to contact during follow-up visit, or

- Death.

Source of data

Patient's medical records.

\section{Study procedure}

The Institutional Ethical Committee clearance was obtained from the Institutional Ethical Review Committee Ref. No. SJMCP/922B/2014-15. Besides, informed consent was taken from the participants, after explaining the objectives, procedures, and benefits of the study in local language. The information was collected from hospital inpatients of various departments (medicine, surgery, orthopedics, psychiatry, skin, RNTCP centre, ophthalmology, ear nose throat, obstetrics, and gynecology) and old-age home in a pre-structured case record form. The patients who gave the consent to participate in the study were included in the study. Sociodemographic and economic status - modified BG Prasad scale [6], clinically diagnosed disease classification by International Classification of Diseases Class 10 [7] and medication details were obtained from medical records, considering whole therapy as one prescription and drugs were classified based on Anatomical Therapeutic Chemical classification code system [8] and assessed for prescribing pattern. 
Statistical analysis

The results were expressed as frequency and percentage using MS-Excel.

\section{RESULTS AND DISCUSSION}

It is a challenging task for health professionals to treat geriatric patients. The present study was carried out on geriatric patients, admitted in BMCH and RC and old-age home, Chitradurga. A total of 526 patients were included in the study by considering the study criteria. A majority of patients were young older age group 65-74 years (75.29\%). The male geriatric patient's preponderance was more $55.89 \%$ than females $44.11 \%$ as mentioned in Table 1 . The similar results were observed with more $51 \%$ of young older and more $53 \%$ of male geriatric patients in Anjum et al. study [9]. The mean age of geriatric patients was 70 years in the present study.

Sociodemographic and economic details in the current research showed more young older geriatrics than middle older and old older, while comparison of educational level, literate $51.71 \%$ were more than illiterate $48.29 \%$, and for occupational level, stay at home $50.57 \%$ were more than employed $49.43 \%$, whereas Class V (lower class) $42.21 \%$ of geriatric patients were more, followed by Class I (high class) $30.42 \%$, Class II (upper middle class) 20.91\% than Class III (middle class) $5.51 \%$, and Class IV (lower middle class) $0.95 \%$ in economic class comparison. While, Singh study results also showed more percent of literate, working and economically middle class geriatric patients, than illiterate, not working and middle class or upper middle class respectively [10]. The number of clinical diagnosis, in geriatric patients with multiple morbidity $53.42 \%$ (comorbidity), was more than single morbid condition 46.58\%. The details are presented in Graph 1.

Among the diseases diagnosed percentage of patients with circulatory system affecting diseases (I00-I99) were more $41.83 \%$ followed by respiratory system (J00-J99) (35.36\%), endocrine, nutritional, and metabolic diseases (E00-E90) (28.33\%), certain infectious and parasitic diseases (A00-B99) (13.88\%), digestive system (K00-K93) (10.46\%), blood and blood-forming organ diseases (D50-D89) (9.51\%), drugs, medicaments, and biological substances poisoning (T36-T50) 8.17\%, genitourinary system diseases (N00-N99) (7.98\%), diseases of musculoskeletal system and connective tissue (M00-M99) (7.41\%), diseases of the nervous system (G00-G99) (5.13\%), diseases of the skin and subcutaneous tissue (L00-L99) (3.23\%), neoplasm (C00-D49) (2.85\%), diseases of the ear and mastoid process (H60-H95) (1.14\%), mental and behavioral disorders (F00-F99) (1.14\%), shock (R57) $(0.57 \%)$, and factors influencing health status and contact with health services (Z47.2) (0.13\%) details presented in Graph 2. The non-communicable disease burden in the elderly was found to be more in recent health survey; cardiovascular diseases contributed more than the other group of morbid conditions. Similar, cardiovascular disease cause for admission was common in Singh study [10] and Jhaveri et al. [11], whereas in Nayaka et al. study found more geriatric inpatients with respiratory disorders (66.67\%) followed by diabetes mellitus (35.3\%) and cardiovascular diseases (32.67\%) [12].

Out of 526 prescriptions, 3228 formulations with 357 active drugs were found. Parenteral dosage form (53.06\%) usage was more. The average number of drugs per prescription was 6.14 as presented in Table 2 .

Drugs acting on alimentary tract and metabolism (A) (26.96\%) followed by anti-infectives (J) (19.08\%), respiratory system (R) (15.61\%), cardiovascular system (C) (11.83\%), nervous system (N) (11.65\%), blood

Table 1: Geriatric age and gender distributions $(n=526)$

\begin{tabular}{llll}
\hline Age group (years) & \multicolumn{2}{l}{ Number of patients (\%) } \\
\cline { 2 - 3 } & \multicolumn{2}{l}{ Gender } & Total \\
\cline { 2 - 3 } & Male & Female & \\
\hline $65-74$ & $226(42.97)$ & $170(32.32)$ & $396(75.29)$ \\
$75-84$ & $55(10.46)$ & $54(10.27)$ & $109(20.72)$ \\
$\geq 85$ & $13(2.47)$ & $8(1.52)$ & $21(3.99)$ \\
Total number of & $294(55.89)$ & $232(44.11)$ & $526(100)$ \\
patients $(\%)$ & & & \\
\hline
\end{tabular}

Table 2: Prescribing pattern

\begin{tabular}{ll}
\hline Details & Total \\
\hline $\begin{array}{l}\text { Total number of prescriptions (n) } \\
\text { Total number of formulation } \\
\text { prescribed (x) }\end{array}$ & 526 \\
$\begin{array}{l}\text { Number of active drugs found in } \\
\text { formulations }\end{array}$ & 3228 \\
Average number of medication per & 357 \\
prescriptions (x/n*100) & \\
Number of drugs (n=526) & 6.14 \\
$\quad$ Number of prescription with $\leq 5$ drugs & \\
$\quad$ Number of prescription with $\geq 6$ drugs & \\
Dosage forms (3228) & $230(43.73 \%)$ \\
$\quad \begin{array}{l}\text { Oral dosage } \\
\text { Parenteral dosage }\end{array}$ & $296(56.27 \%)$ \\
$\quad$ Gaseous dosage & $1233(38.20)$ \\
$\quad$ Other dosage & $1713(53.06)$ \\
\hline
\end{tabular}

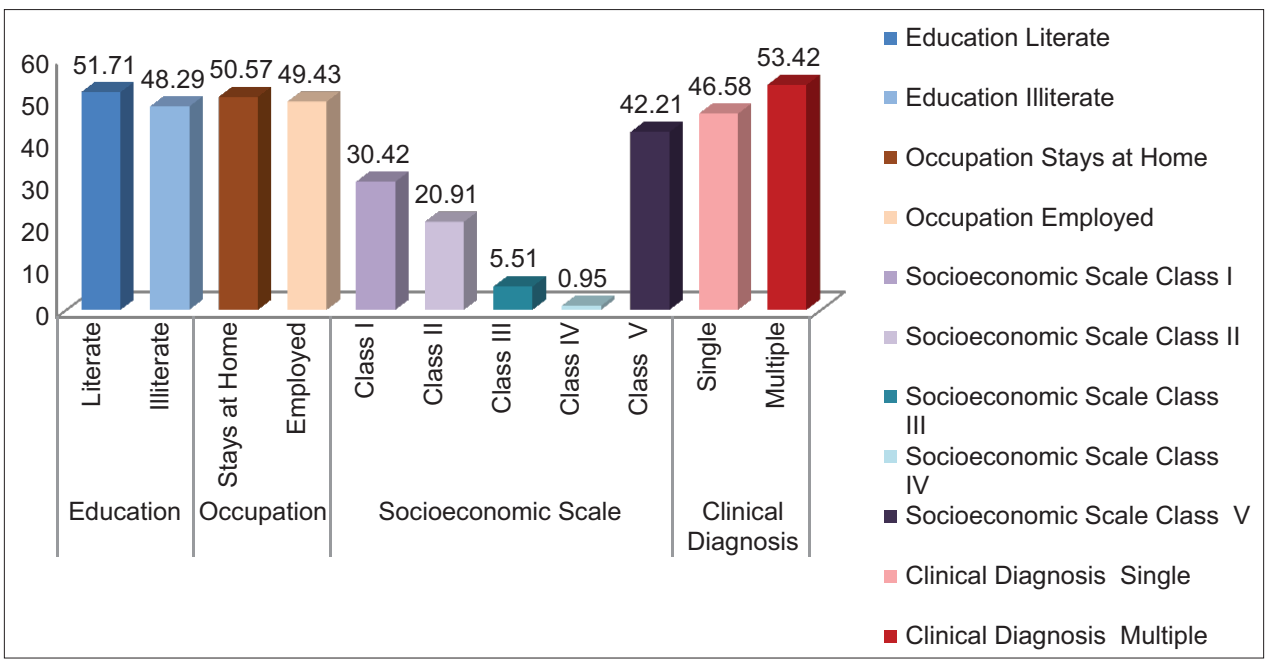

Graph 1: Percentage of geriatric patient's distribution for sociodemographic, economic, and clinical diagnosis 


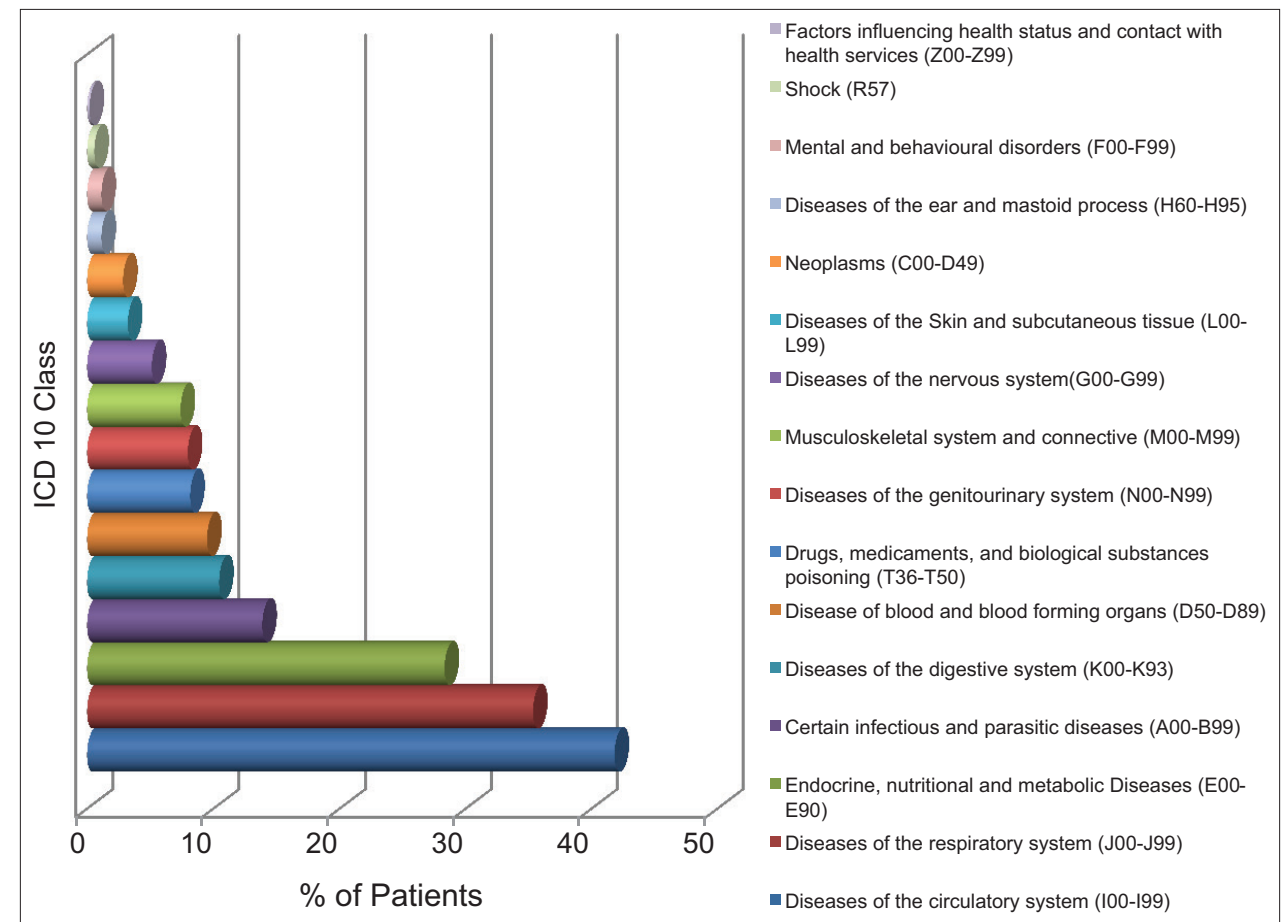

Graph 2: Percentage of patient's distribution based on international classification of diseases 10 classes

Table 3: System wise prescribing pattern of class of drugs based on ATC classification

\begin{tabular}{ll}
\hline $\begin{array}{l}\text { Prescribing pattern of drugs based } \\
\text { on ATC classification (n=3228) }\end{array}$ & $\begin{array}{l}\text { Frequency of } \\
\text { utilization (\%) }\end{array}$ \\
\hline $\begin{array}{l}\text { Alimentary tract and metabolism (A) } \\
\text { General anti-infectives for systemic }\end{array}$ & $871(26.96)$ \\
use (J) & $616(19.08)$ \\
Respiratory system (R) & $504(15.61)$ \\
Cardiovascular system (C) & $382(11.83)$ \\
$\begin{array}{l}\text { Nervous system (N) } \\
\text { Blood and blood-forming organs (B) }\end{array}$ & $376(11.65)$ \\
Musculoskeletal system (M) & $270(8.36)$ \\
$\begin{array}{l}\text { Systemic hormonal preparations, excl. } \\
\text { sex hormones, and insulin (H) }\end{array}$ & $83(2.57)$ \\
Various (V) & $52(1.61)$ \\
Antiparasitic products, insecticides, \\
and repellents (P) & $36(1.12)$ \\
Genitourinary system and sex & $31(0.96)$ \\
hormones (G) & \\
Dermatologicals (D) & $5(0.15)$ \\
\hline
\end{tabular}

$\mathrm{n}=$ total number of formulation and percentage. ATC: Anatomical Therapeutical Chemical

and blood-forming organs (B) (8.36\%), musculoskeletal system (M) (2.57\%), systemic hormonal preparations, excl. sex hormones, and insulin (H) (1.61\%), various (V) (1.12\%), antiparasitic products, insecticides, and repellents $(\mathrm{P})(0.96 \%)$, genitourinary system and sex hormones $(\mathrm{G})$ $(0.15 \%)$, and dermatological (D) $(0.06 \%)$ were commonly prescribed class of drugs as shown in Table 3. Sultan et al. study showed an average of 7.09 drugs per prescription and $56.27 \%$ of patients were prescribed with $\geq 6$ medications (polymedication) and more usage of drugs, acting on respiratory system, followed by gastrointestinal tract, analgesics and anti-inflammatory drugs, antimicrobial drugs, and cardiovascular diseases [13]. Prakash et al. reported more polypharmacy prescriptions followed by more usage of antibiotics and gastrointestinal drugs [14]. Chowta et al. carried out a cross-sectional study which also revealed $31.66 \%$ of geriatrics patients received significant polypharmacy $(\geq 6)[15]$.
Table 4: Top 25 commonly prescribed drugs

\begin{tabular}{lll}
\hline Drug (s) (n=3228) & $\begin{array}{l}\text { ATC } \\
\text { code }\end{array}$ & $\begin{array}{l}\text { Frequency of drug } \\
\text { utilization (\%) }\end{array}$ \\
\hline Pantoprazole & A02BC02 & $269(8.33)$ \\
Paracetamol & N02BE01 & $188(5.82)$ \\
Ceftriaxone & J01DD04 & $173(5.03)$ \\
Ipratropium & R03AL02 & $130(3.84)$ \\
bromide+Levosalbutamol & & \\
Theophylline+Etofylline & R03DA54 & $124(3.84)$ \\
Ondansetron & A04AA01 & $122(3.78)$ \\
Furosemide & C03CA01 & $92(2.85)$ \\
Budesonide & R01AD05 & $90(2.79)$ \\
Rabeprazole & A02BC01 & $88(2.73)$ \\
Insulin & A10AD01 & $86(2.66)$ \\
Piperacillin+Tazobactam & J01CR05 & $73(2.26)$ \\
Ranitidine & A02BA02 & $69(2.14)$ \\
Sodium chloride & B05CB01 & $69(2.14)$ \\
Azithromycin & J01FA10 & $63(1.95)$ \\
Ceftriaxone+Tazobactam & J01DD63 & $50(1.55)$ \\
Diclofenac sodium & M01AB05 & $47(1.46)$ \\
Atorvastatin & C10AA05 & $45(1.39)$ \\
Metronidazole & J01XD01 & $41(1.27)$ \\
Tramadol & N02AX02 & $36(1.12)$ \\
Aspirin+Clopidogrel & B01AC30 & $33(1.02)$ \\
Ramipril & C09AA05 & $33(1.02)$ \\
Telmisartan & C09CA07 & $33(1.02)$ \\
Levofloxacin & J01MA12 & $32(0.99)$ \\
Amlodipine & C08CA01 & $30(0.93)$ \\
Salbutamol & R03AC02 & $28(0.87)$ \\
\hline
\end{tabular}

$\mathrm{n}=$ total number of formulation, ${ }^{, A}$ Anatomical Therapeutic Chemical classification and percentage . ATC: Anatomical Therapeutical Chemical

In the current study, most commonly prescribed top 25 drugs were pantoprazole (A02BC02) 269 (8.33\%), paracetamol (N02BE01) 188 (5.82\%), ceftriaxone (J01DD04) 173 (5.03\%), ipratropium bromide+levosalbutamol (R03AL02) 130 (3.84\%), theophylline+etofylline (R03DA54) 124 (3.84\%), ondansetron (A04AA01) 122 (3.78\%), furosemide (C03CA01) 92 (2.85\%), budesonide (R01AD05) 90 (2.79\%), rabeprazole (A02BC01) 88 $(2.73 \%)$, insulin (A10AD01) 86 (2.66\%), piperacillin+tazobactam 
(J01CR05) 73 (2.26\%), ranitidine 69 (A02BA02) (2.14\%), sodium chloride (B05CB01) 69 (2.14\%), azithromycin (J01FA10) 63 (1.95\%), ceftriaxone+tazobactam (J01DD63) 50 (1.55\%), diclofenac sodium (M01AB05) 47 (1.46\%), atorvastatin (C10AA05) 45 (1.39\%), metronidazole (J01XD01) 41 (1.27\%), tramadol (N02AX02) 36 $(1.12 \%)$, aspirin+clopidogrel (B01AC30) 33 (1.02\%), ramipril (C09AA05) 33 (1.02\%), telmisartan (C09CA07) 33 (1.02\%), levofloxacin (J01MA12) 32 (0.99\%), amlodipine (C08CA01) 30 $(0.93 \%)$, and salbutamol (R03AC02) $28(0.87 \%)$ as mentioned in Table 4 . Shah et al. carried cross-sectional prospective observational rural study on drug utilization involving 400 geriatric patients 200 each from inpatients and outpatients. The results showed that drugs acting on the cardiovascular system $(22.81 \%)$ were the most frequently prescribed followed by antimicrobials (16.89\%) and drugs acting on the gastrointestinal system (13.61\%). Ranitidine was (A02BA02) most frequently prescribed drug, followed by aspirin (B01AC06), diclofenac sodium (M01AB05), and amlodipine (C08CA01) [16] whereas Singh drug utilization pattern showed that cardiovascular drugs $(22.17 \%)$ were most frequently prescribed followed by gastrointestinal drugs (15.30\%). Among individual drugs, pantoprazole (A02BC02) was most commonly prescribed [10].

\section{CONCLUSION}

The study concludes the need of introspection for the usage of parenteral dosage form, gastrointestinal, and antimicrobial class of drugs. The intellect prescribing practice is necessary to install more rational therapy.

\section{ACKNOWLEDGMENT}

The authors are thankful to the management of SJM Vidyapeetha ${ }^{\circledR}$ and old-age home, Chitradurga, for providing necessary facilities.

\section{AUTHORS' CONTRIBUTIONS}

Nataraj GR designed the research work, collected the data, analyzed the data, and cowrote the paper. Bharathi DR designed the research work, analyzed the data, and cowrote the paper.

\section{CONFLICTS OF INTEREST}

Declare none.

\section{REFERENCES}

1. Bressler R, Bahl JJ. Principles of drug therapy for the elderly patient. Mayo Clin Proc 2003;78:1564-77.

2. Helena G. Drug utilization studies. Arq Med 2008;22:69-74

3. World Health Organization. Introduction to Drug Utilization Research. Geneva: World Health Organization; 2003.

4. United Nations Population Division (UN). World Population Prospects: The 2010 revision. New York: United Nations; 2011.

5. McLean AJ, Le Couteur DG. Aging biology and geriatric clinical pharmacology. Pharmacol Rev 2004;56:163-84

6. Singh T, Sharma S, Nagesh S. Socio-economic status scales updated for 2017. Int J Res Med Sci 2017;5:3264-7.

7. WHO. International Statistical Classification of Diseases and Related Health Problems. 10 ${ }^{\text {th }}$ revision: WHO; 2014.

8. WHO Collaborating Centre for Drug Statistics Methodology. Guidelines for ATC classification and DDD assignment.16 ${ }^{\text {th }}$ ed. Oslo: WHO; 2012, 2013.

9. Anjum MS, Jacob C, Benchamin A, Rodrigues PA. A prospective study on geriatric prescribing pattern and medication adherence in a tertiary care hospital. Asian J Pharm Clin Res 2017;10:220-5.

10. Singh NG. To assess the drug utilization pattern and to analyze pharmacoeconomics for geriatrics in-patient in medicine department of tertiary care teaching hospital. Int J Pharm Pharm Sci 2017;09:276-82.

11. Jhaveri BN, Patel TK, Barvaliya MJ, Tripathi CB. Drug utilization pattern and pharmacoeconomic analysis in geriatric medical inpatients of a tertiary care hospital of India. J Pharmacol Pharmacother 2014;5:15-20.

12. Nayaka SR, Rajeshwari B, Venkatadri TV. Drug utilization pattern in geriatric inpatients of medicine department in a tertiary care teaching hospital. Int J Basic Clin Pharmacol 2015;4:568-73.

13. Sultan H, Sayegh K, Mohammad A, Hussain S, Sumaily J, Agarwal M, et al. Prescribing pattern of drugs in the geriatric patients in Jazan province, KSA. Pharm Pharmacol Int J 2015;2:00013.

14. Prakash G, Yalavarthi K, Sharan EJ, Justin J, Krishna MS. A prospective study on medication prescribing pattern for geriatric patients in a tertiary care teaching hospital. Asian J Biomed Pharm Sci 2016;6:23-7.

15. Chowta MN, Adhikari PM, Raj S, Laxman M, Kariappa A, George J, et al. Evaluation of appropriateness of prescription and poly pharmacy in the geriatric population: A cross-sectional study at a comprehensive geriatric clinic in a tertiary care hospital. Int $\mathrm{J}$ Pharm Pharm Sci 2016;08:119-23.

16. Shah RB, Gajjar BM, Desai SV. Drug utilization pattern among geriatric patients assessed with the anatomical therapeutic chemical classification defined daily dose system in a rural tertiary care teaching hospital. Int J Nutr Pharmacol Neurol Dis 2012;02:258-65. 